\title{
Treatment of C-section diverticula with hysteroscopic resection in women without childbearing intention: a retrospective cohort study
}

Hui Shi', Jingyan $\mathrm{He}^{2}$, Yunhe Gao², Shuang Qin², Jiaying Fan², Qing Xiao², Kuanrong $\mathrm{Li}^{1}$ and Huiying Liang ${ }^{1 *}$

\begin{abstract}
Background: Diverticulum, one of the long-term sequelae of cesarean section, can cause abnormal uterine bleeding, dysmenorrhea and chronic pelvic pain. Hysteroscopic resection of diverticula is thought to reduce abnormal uterine bleeding and chronic pelvic pain. In this study, we aim to describe the improvement after hysteroscopic resection of cesarean section diverticula (CSD) in women without childbearing intention, and to explore the variables associated with poor prognosis.
\end{abstract}

Methods: A retrospective cohort study of women aged 25-48 with CSD diagnosis by transvaginal ultrasonography (TVS) and hysteroscopy that were enrolled at Guangzhou Women and Children's Medical Center between June 2017 and December 2018. A total of 124 women met the inclusion criteria and all patients had undergone hysteroscopic resection and accepted a follow-up interview at the 3rd and 6th months postoperatively to record symptom improvement.

Result: The mean of intraoperative blood loss and operative time of hysteroscopic resection were $(12.94 \pm 12.63) \mathrm{ml}$ and $(33.63 \pm 6.87)$ min in 124 patients. Overall observed improvement rates of CSD symptom were 47.2 and $65.6 \%$ in the first 3 and 6 months, respectively. Multivariable logistic regression models revealed that timing of surgery $<14$ days was a good prognostic factor associated with both 3-month improvement $(\mathrm{OR}, 16.59 ; 95 \% \mathrm{Cl}, 2.62-$ $104.90 ; P=0.003)$ and 6-month improvement $(\mathrm{OR}, 15.51 ; 95 \% \mathrm{Cl}, 1.63-148.00 ; P=0.02)$; Patients with numbers of cesarean section (CS) $\geq 2$ had a lower rate of improvement after 6 months of CSD repair surgery compared with patients who underwent one CS (OR, 8.29; 95\%Cl, 1.05-65.75; $P=0.04)$.

Conclusions: A hysteroscopic repair might be an appropriate method for CSD in women who no childbearing intentions. The timing of surgery and the number of CS seems to be factors influencing the postoperative improvement of CSD.

Keywords: Cesarean section diverticulum, Cohort study, Hysteroscopic, Prognostic factor

\footnotetext{
* Correspondence: lianghuiying@hotmail.com

'Institute of Pediatrics, Guangzhou Women and Children's Medical Center,

Guangzhou Medical University, 9 Jinsui Road, Zhujiang Newtown, Tianhe

District, Guangzhou 510623, China

Full list of author information is available at the end of the article
}

(C) The Author(s). 2020 Open Access This article is licensed under a Creative Commons Attribution 4.0 International License, which permits use, sharing, adaptation, distribution and reproduction in any medium or format, as long as you give appropriate credit to the original author(s) and the source, provide a link to the Creative Commons licence, and indicate if changes were made. The images or other third party material in this article are included in the article's Creative Commons licence, unless indicated otherwise in a credit line to the material. If material is not included in the article's Creative Commons licence and your intended use is not permitted by statutory regulation or exceeds the permitted use, you will need to obtain permission directly from the copyright holder. To view a copy of this licence, visit http://creativecommons.org/licenses/by/4.0/. The Creative Commons Public Domain Dedication waiver (http://creativecommons.org/publicdomain/zero/1.0/) applies to the data made available in this article, unless otherwise stated in a credit line to the data. 


\section{Background}

Owing to the growing Caesarean section (CS) rate, the incidence of cesarean section diverticulum (CSD), a common complication of CS, is expected to increase as well [1]. CSD is defined as deficient uterine scars or scar dehiscence following a cesarean section, which involves the myometrial discontinuity at the cesarean scar [2]. In a meta-analysis of 21 studies involving nearly 2500 participants, the prevalence of CSD varies between 56 and $84 \%$ [3]. Although a clear definition of CSD is still the subject of some debate, abnormal uterine bleeding, prolonged menstrual bleeding, dysmenorrhea and chronic pelvic pain are generally accepted as the common symptoms [4-7]. These symptoms can seriously affect patients' quality of life. Furthermore, the clinical implications of CSD due to possible CS scar ectopic pregnancy and a potentially higher risk of uterine rupture are of concern to obstetricians and gynecologists [1].

At present, the treatment of CSD includes hormonal contraceptive therapy and surgery. However, oral contraceptives can only result in a temporary improvement in symptoms [8, 9]. Thus, several surgical therapies have been developed including laparoscopic or hysteroscopic defect resection and vaginal defect repair [10]. Hysteroscopic resection is considered the least invasive among these operations, so far only a few studies reported on a hysteroscope resection of the CSD. Among them van der Voet et al. systematically reviewed the available literature and concluded that sample sizes, follow-up, and methodological quality of the selected papers were insufficient to draw solid conclusions [10].. Before hysteroscopic resection is implemented in women that suffer from postmenstrual spotting based on a CSD, better assessment of the effectiveness of the treatment is needed.

In this study, our aim is to describe the improvement after hysteroscopic resection of CSD and to explore the variables associated with poor prognosis.

\section{Methods}

\section{Study population}

The protocol of this retrospective cohort study was approved by the ethics committee of the Guangzhou Women and Children's Medical Center between June 2017 and December 2018 (No. GO-2017-017). The requirement to obtain informed consent was waived because of the retrospective nature of the study, but an oral consent was obtained from some subjects at the time of telephone follow-up after full explanation of the purpose and nature of the procedure used.

All the enrolled patients fulfilled the following criteria: (1) history of at least one CS; (2) no childbearing intention; (3) residual myometrial thickness (RMT) at least $3 \mathrm{~mm}$ [11]; (4) diagnosed with CSD. by transvaginal ultrasonography (TVS) and hysteroscopy [12], and manifested clinical symptoms including prolonged menstrual, increase in menstrual volume, abdominal pain or irregular bleeding. Exclusion criteria included: (1) irregular menstrual cycle before CS; (2) previous intrauterine contraceptive device localization; (3) coagulation disorders; (4) abnormal uterine bleeding resulted from other organic uterine pathology, e.g., endometrial hyperplasia/ polyps, malignancy, or submucosal myomas.

\section{Diagnosis and treatment of CSD}

The diagnosis of CSD was established by TVS and hysteroscopy. All TVS were performed by a team with three ultrasound operators, and sonograms display a triangular anechoic filling defect. We measured the length, width, depth and RMT of CSD (Fig. 1). The experienced gynecologists performed hysteroscopy which shows the uterine anterior wall defect at the isthmus, to identify the presence of CSD in the isthmic or cervical site. All ultrasound operators and gynecologists have undergone unified, standardized training.

All CSD patients in the current study were initially treated with the standard regimen at the time they first presented to the clinic (Drospirenone-Ethinyl Estradiol tablet -Yasmin, containing $3.0 \mathrm{mg}$ of drospirenone and $0.03 \mathrm{mg}$ of ethinylestradiol, continued for 3 cycles of 21 days). However, their symptoms had not improved and need to be treated in surgical treatment.

For each patient, decisive diagnoses repair of CSD was performed by a gynecologist follow the procedures as described below: under combined spinal and epidural anesthesia, patients were placed in a dorsal lithotomy position and the bladder was emptied. After sterile preparation and bladder catheterization, the cervix uteri was visualized using a vaginal retractor, and the anterior lip of the cervix was held with grasping forceps. A bipolar electrode (size: $9 \mathrm{~mm}$ ) was then introduced under direct visualization via hysteroscopy (Olympus UES 40, Olympus, Japan). Physiological saline solution was used as a medium of uterine distension. After determining where the diverticulum was located, we performed a resection of inferior edges of the defect using a cutting loop. The bottom of the pouch was treated by use of aimed electrocauterization with a roller-ball 3-mm. At the same time, the endometrial tissue was taken for biopsy to rule out the presence of endometrial lesions, such as endometrial polyps, intimal hyperplasia, and endometrial cancer (Fig. 2).

\section{Data acquisition and patient follow-up}

Baseline data from medical records contained patient demographics, surgical details, menstruation, and reproductive history. Length, width, depth, and RMT of the diverticulum will be registered through TVS. All patients were followed up in the 3rd and 6th month after surgery 


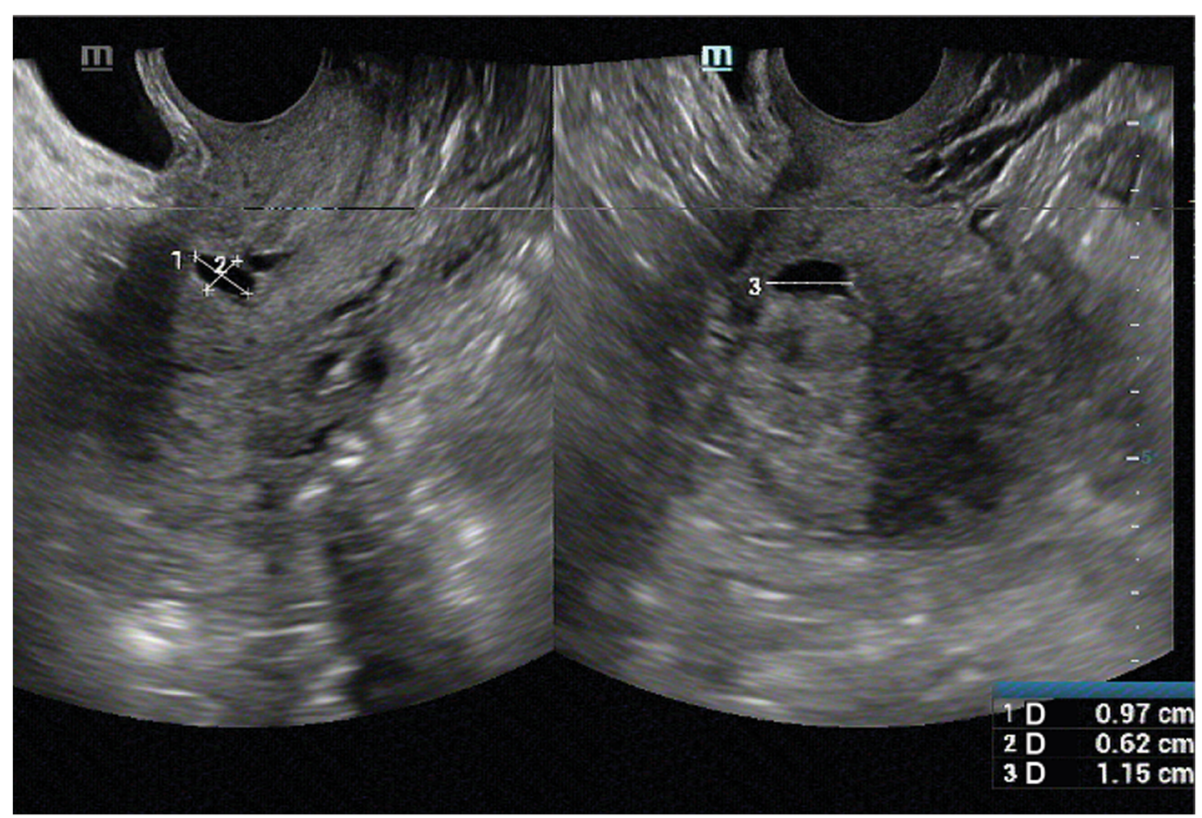

Fig. 1 Ultrasound images of a cesarean scar defect. Size of scar defect (Length* Width* Depth):9.7* $11.5 * 6.2 \mathrm{~mm}$

according to the established clinical pathways. Assessments about the improvement of CSD related symptoms (menstrual duration, menstrual volume, abdominal pain, and irregular bleeding) were mainly performed by a hospital visit. When follow-up assessments were not reported in the clinic medical records, telephone interviews were conducted by an obstetrician with at least 5 years of experience (Telephone interviews guide, see Additional file 1). The timing of surgery was defined as the interval between the first day of menstruation when blood starts to come out of the vagina and surgical treatment date.

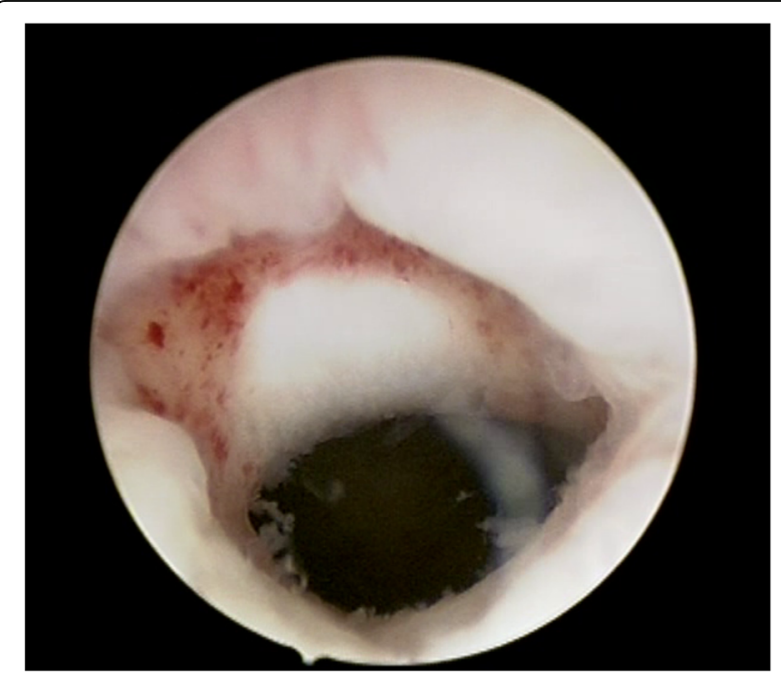

Fig. 2 Hysteroscopic appearance of a cesarean scar defect

\section{Outcome measures}

The outcome was a postoperative improvement of CSD related symptoms. In this study, an improvement was defined as: (1) the postoperative menstrual duration shortened to $<7$ days or 2 days shorter than the previous duration before surgery, or (2) alleviation of irregular bleeding, abdominal pain, and vaginal discomfort.

\section{Statistical analysis}

Standard descriptive statistics were used, including percentages for discrete variables and mean \pm SD for continuous variables. Categorical data were analyzed using the chi-square test, and continuous data using the independent samples t-test or Wilcoxon rank-sum test where appropriate. Logistic regression was used to evaluate prognostic factors of CSD recovery. The receiveroperating characteristics (ROC) curve was used to indicate the predictive role of the timing of surgery in CSD recovery. The area under curve (AUC) was calculated with its 95\% CI. All reported $P$ values are two-sided, and a $P$ value of less than 0.05 was considered statistically significant. Statistical analysis was performed using SPSS 19.0.

\section{Results}

\section{Patient characteristics}

As shown in the flowchart, 165 consecutively eligible patients with one surgeon were initially enrolled, and 124 patients were included in the final study. There were 18 and 10 patients were lost to follow-up at 3 and 6 months after CSD, respectively. (Fig. 3). 


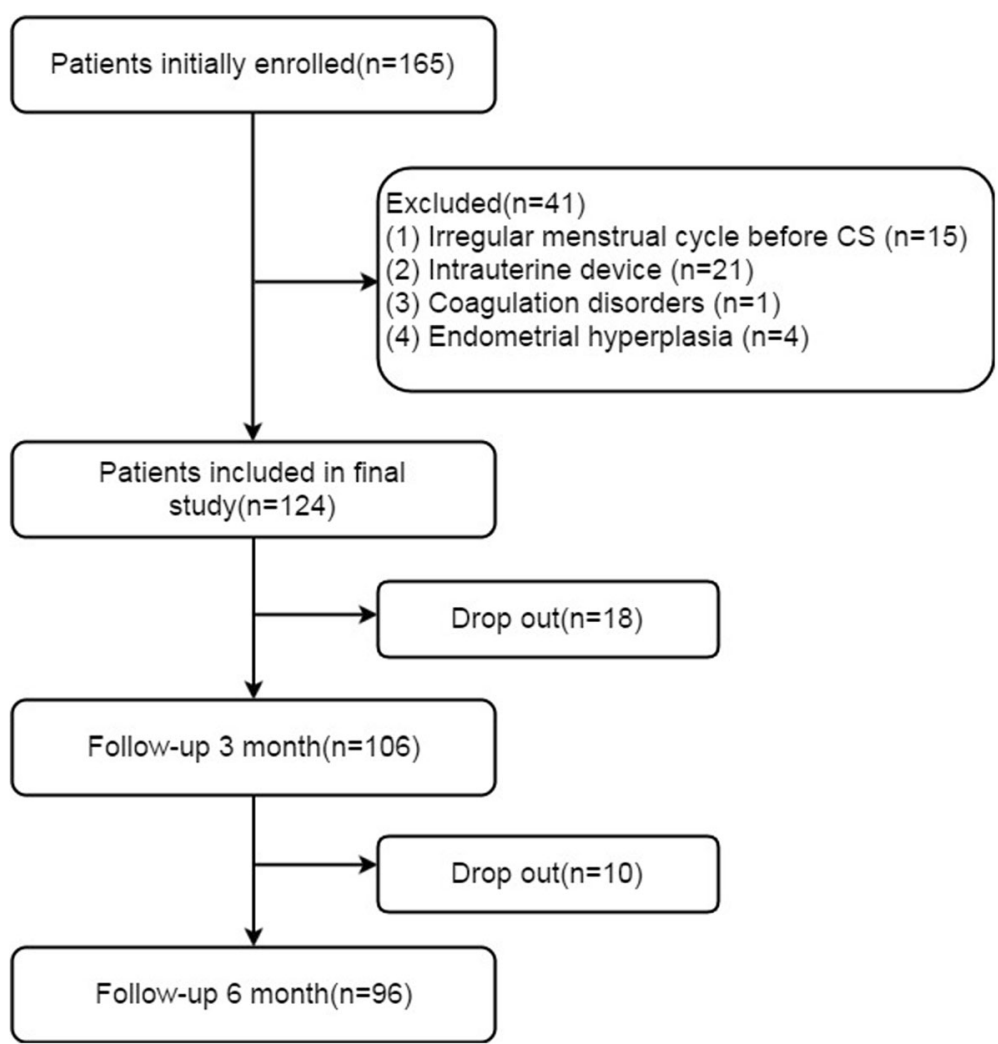

Fig. 3 Flow diagram detailing the patients included in the retrospective analysis

Baseline characteristics of the patients before surgery of CSD are shown in Table 1 . The average age of the patients was $35.0 \pm 5.0$ years (range 25-48), the mean of menarche age was $13.6 \pm 1.3$ years, and the mean of duration between symptom onset and surgery was $3.0 \pm 2.8$ years. A total of $63(50.8 \%)$ patients had undergone $\geq 2$ deliveries by CS. Doppler ultrasound data showed that the mean length, width, depth, and RMT of the scar defects before the operation were $9.7 \pm 6.7 \mathrm{~mm}, 8.1 \pm 7.3 \mathrm{~mm}, 8.7 \pm 5.9 \mathrm{~mm}$, and $4.9 \pm 2.1 \mathrm{~mm}$, respectively.

At the same time, we assessed the amount of blood loss and operation time of the patients during surgery, the mean of intraoperative blood loss and operative time were $(12.94 \pm 12.63) \mathrm{ml}$ and $(33.63 \pm 6.87) \mathrm{min}$ of 124 patients.

\section{The improvement after CSD surgical treatment}

The proportion of patients who reported improvement of menstrual symptoms after CSD repair was $47.2 \%$ (50/ 106) within 3 months, and $65.6 \%(63 / 96)$ within 6 months. Compared with preoperative, the proportion of patients with more menstrual duration, much menstrual volume, and irregular bleeding decreased significantly at 3 months and 6 months after surgery $(P<0.05)$. A significant improvement in the irregular bleeding was observed in the 3,6 months after surgery $(P<0.05)$. However, there was no significant difference in menstrual volume and abdominal pain between the two periods $(P=0.67$, $P=0.07$ ) (Table 2).

\section{Comparison of clinical parameters between the improvement group and no improvement group at 3 months and 6 months after CSD}

Table 1 also shows the characteristics of the improvement and no improvement groups in both 3 months and 6 months. These characteristics were generally similar in the two groups except the number of CS, abortion times, and timing of surgery. Patients who had undergone $\geq 2$ CS were more likely to have no improvement compared with those who had one CS at 3 months and 6 months $\left(P_{3 m}=0.04, P_{6 m}=0.004\right)$, and lower times of abortions were associated with a higher chance of improvement at 6 months $\left(P_{6 m}=0.01\right)$. The timing of surgery was significantly shorter in the improvement group when compared with that of the no improvement group within both 3 months and 6 months $\left(P_{3 \mathrm{~m}}=0.002, \mathrm{P}_{6 \mathrm{~m}}=0.03\right)$.

On receiver-operating characteristic curve analyses, the timing of surgery had significant performance in predicting CSD at 3 months (AUC, 0.70; 95\% CI, 0.60-0.79) and 6 months (AUC, 0.68; 95\% CI, 0.57-0.78) postoperative improvement, as shown in Fig. 4. 
Table 1 Baseline demographics and clinical characteristics for patients between improvement and no improvement group

\begin{tabular}{|c|c|c|c|c|c|c|c|}
\hline \multirow[t]{2}{*}{ Characteristics } & \multirow{2}{*}{$\begin{array}{l}\text { Total }(n= \\
124)\end{array}$} & \multicolumn{2}{|c|}{3 months $(n=106)$} & \multirow[b]{2}{*}{$P_{3 m}{ }^{a}$} & \multicolumn{2}{|c|}{6 months $(n=96)$} & \multirow[b]{2}{*}{$P_{6 m}{ }^{a}$} \\
\hline & & Improvement & No Improvement & & Improvement & No Improvement & \\
\hline Age (years) & $35.0 \pm 5.0$ & $34.7 \pm 4.8$ & $35.4 \pm 5.5$ & 0.50 & $34.5 \pm 4.7$ & $35.4 \pm 6.1$ & 0.42 \\
\hline Age of menarche (years) & $13.6 \pm 1.3$ & $13.5 \pm 1.1$ & $13.7 \pm 1.3$ & 0.51 & $13.5 \pm 1.1$ & $13.8 \pm 1.4$ & 0.29 \\
\hline $\begin{array}{l}\text { Duration between symptom onset } \\
\text { and surgery (years) }\end{array}$ & $3.0 \pm 2.8$ & $3.2 \pm 2.8$ & $3.0 \pm 3.1$ & 0.77 & $2.9 \pm 2.3$ & $3.3 \pm 3.6$ & 0.52 \\
\hline Yeas between CS and surgery (years) & $7.0 \pm 3.7$ & $7.3 \pm 3.5$ & $7.5 \pm 4.2$ & 0.80 & $6.8 \pm 2.9$ & $7.8 \pm 4.3$ & 0.18 \\
\hline \multicolumn{8}{|l|}{ Number of CS } \\
\hline 1 & $61(49.2 \%)$ & $23(46.0 \%)$ & $16(28.6 \%)$ & 0.04 & $31(49.2 \%)$ & $7(21.2 \%)$ & 0.004 \\
\hline$\geq 2$ & $63(50.8 \%)$ & $27(54.0 \%)$ & $40(71.4 \%)$ & & $32(50.8 \%)$ & $26(78.8 \%)$ & \\
\hline Abortion times & $1.0 \pm 1.1$ & $0.9 \pm 1.0$ & $1.2 \pm 1.0$ & 0.12 & $0.8 \pm 0.9$ & $1.4 \pm 1.1$ & 0.01 \\
\hline Surgical timing (days) & $14.2 \pm 5.5$ & $12.0 \pm 4.8$ & $15.3 \pm 5.8$ & 0.002 & $11.7 \pm 4.6$ & $14.3 \pm 5.8$ & 0.03 \\
\hline \multicolumn{8}{|l|}{ Size of scar defects (mm) } \\
\hline Length & $9.7 \pm 6.7$ & $9.1 \pm 8.3$ & $9.5 \pm 4.5$ & 0.75 & $9.4 \pm 7.8$ & $9.3 \pm 7.8$ & 0.98 \\
\hline Width & $8.1 \pm 7.3$ & $8.5 \pm 9.3$ & $7.6 \pm 5.3$ & 0.53 & $7.9 \pm 7.8$ & $6.7 \pm 4.0$ & 0.45 \\
\hline Depth & $8.7 \pm 5.9$ & $8.8 \pm 5.3$ & $9.2 \pm 6.1$ & 0.78 & $8.9 \pm 5.9$ & $8.6 \pm 5.7$ & 0.78 \\
\hline RMT & $4.9 \pm 2.1$ & $5.3 \pm 2.3$ & $4.9 \pm 2.1$ & 0.48 & $5.1 \pm 2.3$ & $4.9 \pm 2.1$ & 0.77 \\
\hline $\mathrm{BMI}\left(\mathrm{kg} / \mathrm{m}^{2}\right)$ & $21.3 \pm 2.6$ & $21.0 \pm 2.4$ & $21.5 \pm 2.7$ & 0.23 & $21.5 \pm 3.1$ & $21.0 \pm 2.4$ & 0.39 \\
\hline Hemoglobin(g/L) & $119.0 \pm 14.7$ & $118.7 \pm 16.0$ & $119.3 \pm 13.6$ & 0.83 & $118.1 \pm 17.9$ & $119.4 \pm 13.2$ & 0.64 \\
\hline \multicolumn{8}{|l|}{ Anemia } \\
\hline Yes & $31(25.0 \%)$ & $11(22.0 \%)$ & $14(25.0 \%)$ & 0.94 & $13(20.6 \%)$ & $10(30.3 \%)$ & 0.22 \\
\hline No & $93(75.0 \%)$ & $39(78.0 \%)$ & $42(75.0 \%)$ & & $50(79.4 \%)$ & $23(69.7 \%)$ & \\
\hline
\end{tabular}

CS caesarean section, RMT residual myometrial thickness

${ }^{a}$ mean \pm SD for continuous variables and percentages for discrete variables

\section{Prognostic factors of CSD recovery}

Multivariable logistic regression showed that the postoperative improvement rate for the timing of surgery< 14 days group was significantly better than that for the group of $\geq 14$ days group at 3 months (OR, 16.59; 95\% CI, 2.62-104.90; $P=0.003)$, similar results were found for post-operative improvement at 6 months (OR, 15.51; 95\% CI, 1.63-148.00; $P=0.02$ ) (Table 3). Besides, the duration between symptom onset and surgery was shorter in the improvement group than in the no improvement group at 6 months (OR, 0.64; 95\% CI, 0.41-0.99; $P=0.04)$. Patients with times of $C S \geq 2$ had a

Table 2 Symptom improvement in patients with cesarean section diverticula 3 and 6 months after hysteroscopic resection ( $n=96$ )

\begin{tabular}{|c|c|c|c|c|c|c|}
\hline Characteristic & Before & 3 months & 6 months & $P_{B-3 m}{ }^{a}$ & $\mathrm{P}_{\mathrm{B}-6 \mathrm{~m}^{\mathrm{a}}}$ & $P_{3 m-6 m^{a}}$ \\
\hline Menstrual duration (day) & $11.5 \pm 4.0$ & $8.8 \pm 3.8$ & $8.0 \pm 3.7$ & $<.001$ & $<.001$ & 0.14 \\
\hline$\leq 7$ (day) & $16(16.7 \%)$ & $45(46.9 \%)$ & $60(62.5 \%)$ & $<.001$ & $<.001$ & 0.03 \\
\hline$>7$ (day) & $80(83.3 \%)$ & $51(53.1 \%)$ & $36(37.5 \%)$ & & & \\
\hline \multicolumn{7}{|c|}{ Menstrual volume (bleeding) } \\
\hline Much & $29(30.2 \%)$ & $16(16.7 \%)$ & $12(12.5 \%)$ & 0.03 & 0.002 & 0.67 \\
\hline Moderation & $56(58.3 \%)$ & $73(76.0 \%)$ & $78(81.3 \%)$ & & & \\
\hline Litter & $11(11.5 \%)$ & $7(7.3 \%)$ & $6(6.3 \%)$ & & & \\
\hline \multicolumn{7}{|l|}{ Abdominal pain } \\
\hline Yes & $23(24.0 \%)$ & $19(19.8 \%)$ & $10(10.4 \%)$ & 0.48 & 0.01 & 0.07 \\
\hline No & $73(76.0 \%)$ & 77 (80.2\%) & $86(89.6 \%)$ & & & \\
\hline \multicolumn{7}{|l|}{ Irregular bleeding } \\
\hline Yes & $51(53.1 \%)$ & $27(28.1 \%)$ & $15(15.6 \%)$ & $<.001$ & $<.001$ & 0.04 \\
\hline No & $45(46.9 \%)$ & $69(71.9 \%)$ & $81(84.4 \%)$ & & & \\
\hline
\end{tabular}

${ }^{a}$ mean \pm SD for continuous variables and percentages for discrete variables 

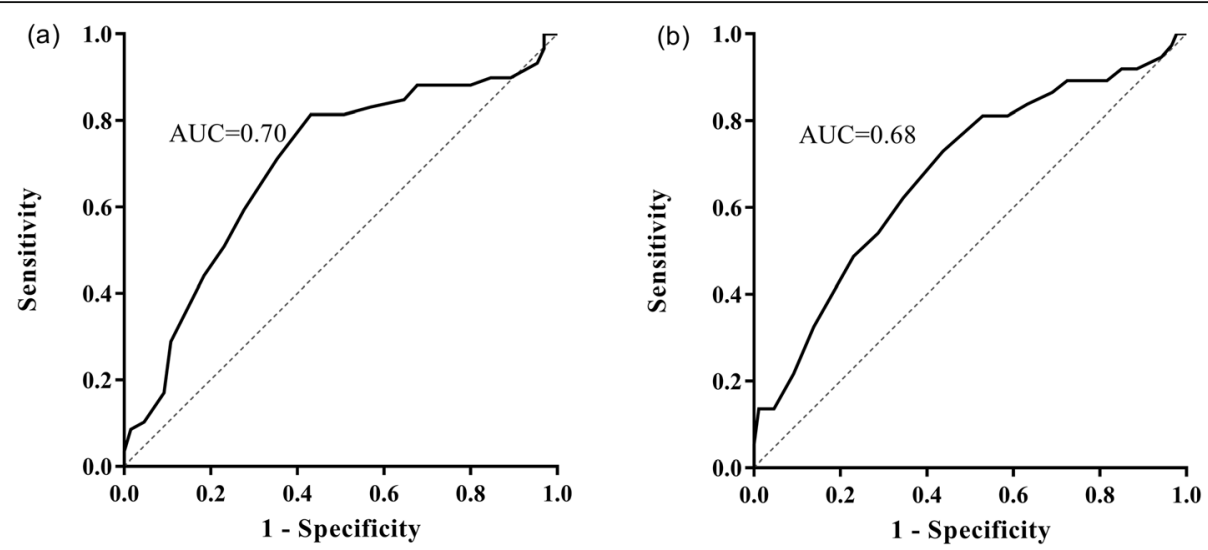

Fig. 4 Receiver-operator characteristic (ROC) curve for the timing of surgery over post-operative improvement at 3 months (a) and 6 months (b)

lower rate of improvement after 6 months of CSD repair surgery compared with patients who underwent one CS (OR, 8.29; 95\% CI, 1.05-65.75; P = 0.04).

\section{Discussion}

Owing to the increasing number of deliveries via CS worldwide, subsequent complications associated with CS, such as prolonged menstruation, irregular genital bleeding, and secondary infertility, have become a considerable concern and treatment for these complications has drawn more and more attention. The association between the diverticulum and bleeding disorders is gradually revealed [13].

Currently, the two main treatment options include hormonal therapy and surgical repair of the diverticulum [14]. Studies reported that CSD related menstrual bleeding disorders or cyclic pain do often not respond to hormonal therapies $[8,9]$. Methods of operative repair of diverticulum include vaginal repair, laparoscopy, and hysteroscopy. The technique of defect

Table 3 Prognostic factors for symptom improvement in patients with cesarean scar defect 3 and 6 months after hysteroscopic resection

\begin{tabular}{|c|c|c|c|c|}
\hline \multirow[t]{2}{*}{ Variables } & \multicolumn{2}{|l|}{3 months } & \multicolumn{2}{|l|}{6 months } \\
\hline & Orrds Ratio $(95 \% \mathrm{Cl})$ & $\mathrm{P}$ & Orrds Ratio $(95 \% \mathrm{Cl})$ & $\mathrm{P}$ \\
\hline Age (years) & $1.12(0.89-1.42)$ & 0.36 & $1.15(0.86-1.53)$ & 0.36 \\
\hline Age of menarche (years) & $0.67(0.37-1.20)$ & 0.17 & $0.61(0.32-1.16)$ & 0.13 \\
\hline Duration between symptom onset and surgery (years) & $0.71(0.46-1.08)$ & 0.11 & $0.64(0.41-0.99)$ & 0.04 \\
\hline Age of CS (years) & $1.26(0.89-1.77)$ & 0.19 & $1.10(0.75-1.59)$ & 0.66 \\
\hline \multicolumn{5}{|l|}{ Number of CS } \\
\hline 1 & 1.00 & & 1.00 & \\
\hline$\geq 2$ & $3.27(0.72-14.88)$ & 0.13 & $8.29(1.05-65.75)$ & 0.04 \\
\hline Abortion number & $0.76(0.34-1.70)$ & 0.50 & $0.53(0.19-1.52)$ & 0.24 \\
\hline \multicolumn{5}{|l|}{ Surgical timing (days) } \\
\hline$<14$ & $16.59(2.62-104.90)$ & 0.003 & $15.51(1.63-148.00$ & 0.02 \\
\hline$\geq 14$ & 1.00 & & 1.00 & \\
\hline Length of defect (mm) & $0.98(0.84-1.13)$ & 0.73 & $0.89(0.74-1.06)$ & 0.19 \\
\hline Width of defect (mm) & $1.02(0.91-1.14)$ & 0.74 & $1.01(0.90-1.29)$ & 0.42 \\
\hline Depth of defect (mm) & $0.94(0.82-1.07)$ & 0.36 & $1.04(0.88-1.23)$ & 0.65 \\
\hline RMT (mm) & $0.94(0.68-1.23)$ & 0.57 & $0.76(0.51-1.11)$ & 0.16 \\
\hline BMI & $0.82(0.60-1.11)$ & 0.20 & $1.39(0.86-2.25)$ & 0.18 \\
\hline \multicolumn{5}{|l|}{ Anemia } \\
\hline Yes & 1.00 & & 1.00 & \\
\hline No & $0.66(0.12-3.72)$ & 0.64 & $0.51(0.06-4.40)$ & 0.54 \\
\hline
\end{tabular}

CS caesarean section, $R M T$ residual myometrial thicknes 
repair through the hysteroscopy used in our clinic results in control of intermenstrual bleeding and pain control. One system review display that hysteroscopy is the most commonly reported approach for the revision of CSD and the existing evidence is inadequate to conclude that either hysteroscopy or laparoscopy is effective or superior to each other [7]. However, hysteroscopy may have a potential risk of decreased resistance of the residual myometrial tissue at the level of the repair and furthermore may lead to uterine rupture during subsequent pregnancy $[15,16]$.

We believed that the choice of the surgical approach is mainly based on the clinical features of patients [17]. In our population, all patients have no plans to conceive again and the residual myometrium thickness should not be less than $3 \mathrm{~mm}$, given the anticipated risk on perforation or bladder injuries [11]. Indeed, we only resected the distal rim of the defect to prevent proximal resection could harm the strength of the cervix and may induce unneeded cervical incompetence. Concurrently superficial coagulation of vessels in the niche aims at reducing blood loss from these fragile vessels.

Under this premise, the cure rate of CSD repair was $47.2 \%$ after 3 months, and $65.6 \%$ after 6 months in our study. However, the cure rate of CSD repair reportedly ranges between 54 and $84 \%$, [3] varying considerably depending on the study. For example, Fabres et al. showed that $84 \%$ of CSD patients (20/ 24) were successfully treated by hysteroscopic surgery after a follow-up of 24 months [18]. In the study of Wang et al., only $59.6 \%$ of patients $(34 / 57)$ reported a postoperative improvement in symptoms after 3 months of surgery [19]. The difference is mainly due to the absence of universal assessment criteria for CSD symptom improvement. Furthermore, data from one study showed that the intraoperative blood loss, operative time of hysteroscopy resection were (10.1 \pm $10.2 \mathrm{ml})$ and $(20 \pm 5.6 \mathrm{~min})$, lower than vaginal repair $(P<0.05)$ and combined laparoscopic and hysteroscopy $(\mathrm{P}<0.05)[20]$. The results of our study are similar to the above (intraoperative blood loss, $12.89 \pm 12.59 \mathrm{ml}$; operative time, $44.73 \pm 17.12 \mathrm{~min}$ ). We and others assume that hysteroscopic resection is more cost-effective. Moreover, in our study, no major complications, such as massive bleeding or uterine perforation, were encountered during surgery.

Our study confirms that a higher number of previous CS is associated with poorly improved symptoms. In the studies cited [21,22], the numbers of scar defects and large scar defects increase as the number of CS increases, the ultrasound examiner found that the more CS, the more difficult it was to evaluate the individual scars, and the number of scars seen at ultrasound imaging did not always correspond to the number of Cesarean sections in women who had undergone more than one Cesarean section. Not all CSD is likely treated completely, and this might explain why patients who had undergone $\geq 2$ CS were more likely to have no improvement compared with those who had one CS.

Clear and broad vision to ensure the successful hysteroscopic surgery of CSD, effective removal of the lower margin of the uterine diverticulum and intimal tissue in the incision is essential, hypertrophic endometrium can affect the surgical field of vision [23], at the same time, the endometrium is thin in the first half of the menstrual cycle due to hormones. Therefore, surgery should be performed in the first half of the menstrual cycle to ensure a clear view of the operation. Obstetrics and Gynecology of Chinese Medical Association Branch proposed the norm about gynecological hysteroscopy, and it suggests that Hysteroscopic surgery should be selected in the early follicular phase of the implementation, 21 which is convenient for operation because of broad vision [24]. Our findings also confirm that poor outcomes were associated with a longer interval between the last menstrual period and the surgical treatment date (timing of surgery), this seems natural because the clear and broad vision of CSD surgery is likely to be an important factor affecting the improvement of postoperative symptoms. Taken together, these findings suggest that the timing of surgery may be an indicator of the incidence of incomplete relief of the performance of the menstrual cycle irregular menstruation after CSD repair.

The present study has several limitations. First, because our study was retrospective, CSD symptom relieve destination for patients was subject to selection bias and unmeasured confounding. This might include factors that determine the severity of CSD, technical factors and processes of surgery, and access to the Guangzhou Women and Children Medical Center, a tertiary obstetrics and gynecology hospital. Second, the small number size of the present study does not allow to extrapolate our findings to other population, and a proportion of patients were lost to follow-up at the 6th month, may lead to an underestimation of the improvement rate. Third, the parameter variables of CSD involved in our study were only the length, width, depth, and RMT, other parameters that may affect the prognosis are not fully considered. Final, the follow-up period (six months) might be too short to generalize our results to longer-term outcomes after CSD. But one recent study suggested that postoperative menstruation and imaging data did not differ markedly between 3 and 6 months after surgery, suggesting that follow-up at 6 months represents an 
adequate endpoint for evaluating the effectiveness of surgery [25].

\section{Conclusion}

Hysteroscopic repair can improve the symptoms of CSD patients and it has the least invasive and quick recovery. However, hysteroscopic repair may be more suitable for those who do not have the willingness to give birth and want to improve their symptoms. It is also more suitable for people with thicker RMT $(\geq 3 \mathrm{~mm})$. The suitable timing of surgery (timing of surgery< 14 days) and the history of CS may be important factors affecting postoperative prognosis.

\section{Supplementary information}

Supplementary information accompanies this paper at https://doi.org/10. 1186/s12905-020-00928-4.

Additional file 1. Questionnaire on the treatment of C-section diverticula with hysteroscopic resection in women without childbearing intention.

\section{Abbreviations}

AUC: Area under curve; CS: Caesarean section; CSD: Cesarean section diverticulum; TVS: Transvaginal ultrasonography; RMT: Residual myometrial thickness; ROC: Receiver-operating characteristics

\section{Acknowledgements}

The authors would like to thank all of the doctors and nurses at the Department of Obstetrics \& Gynaecology, Guangzhou Women and Children's Medical Center.

\section{Authors' contributions}

$\mathrm{HL}, \mathrm{HS}$ and $\mathrm{KL}$ have made substantial contributions to the conception and design, writing and revision of the manuscript. JH, YG, SQ, and QX were responsible for recruitment, enrollment, and follow-up of patients, performed data acquisition, in especial oversaw the sonographic data acquisition. JF interpreted the patient data regarding the C-section diverticula hematological. HL and HS provided the final draft of the manuscript. All authors read and approved the final manuscript.

\section{Funding}

This study was supported by the Guangzhou Institute of Pediatrics/ Guangzhou Women and Children's Medical Center (KCP-2016-002) and the Guangzhou Medical Science Program (20141A011059). All the funding sources of the study had no role in study design, data collection, data analysis, data interpretation, or writing of the manuscript.

\section{Availability of data and materials}

The datasets generated and/or analyzed during the current study are not publicly available due to potential for individual and organizational privacy to be compromised. Reasonable requests for parts of the data will be considered by the corresponding author.

\section{Ethics approval and consent to participate}

Our study is retrospective. All study procedures were approved by the ethics committee of the Guangzhou Women and Children's Medical Center (No. GO-2017-017). We conducted research using identifiable electronic medical record data. The research project did not involve personal privacy and commercial interests and was no longer accessible to participants. Therefore, the ethics committee approved the waiver of signed written informed consent and approved the procedure for verbal consent. At the same time, after obtaining ethical approval, we tried to contact the participants before using the data and notified them by phone. A patient who couldn't be reached by phone, whose data could be used directly. For participants with missing follow-up data, oral informed consent was obtained before the start of each telephone interview. All processes have been recorded and saved. Administrative permissions were required to access and use the medical records described in our study.

\section{Consent for publication}

Not applicable.

\section{Competing interests}

The authors declare that they have no competing interests.

\section{Author details}

${ }^{1}$ Institute of Pediatrics, Guangzhou Women and Children's Medical Center, Guangzhou Medical University, 9 Jinsui Road, Zhujiang Newtown, Tianhe District, Guangzhou 510623, China. ${ }^{2}$ Department of Obstetrics \& Gynaecology, Guangzhou Women and Children's Medical Center, Guangzhou Medical University, Guangzhou, China.

Received: 9 September 2019 Accepted: 18 March 2020

Published online: 21 April 2020

\section{References}

1. Wu, Shun FW. Incidental Findings of Caesarean Section Scar Defect - Case Reports and a Review of its Investigations and Management. J Clin Case Rep. 2015;05(12). https://doi.org/10.4172/2165-7920.1000674.

2. Chen $Y$, Chang $Y$, Yao S. Transvaginal management of cesarean scar section diverticulum: a novel surgical treatment. Med Sci Monit. 2014;20:1395-9. https://doi.org/10.12659/MSM.890642.

3. Bij de Vaate AJ, van der Voet LF, Naji O, Witmer M, Veersema S, Brolmann HA, Bourne T, Huirne JA. Prevalence, potential risk factors for development and symptoms related to the presence of uterine niches following Cesarean section: systematic review. Ultrasound Obstet Gynecol. 2014;43(4):372-82. https://doi.org/10.1002/uog.13199.

4. Naji O, Abdallah Y, Bij De Vaate A, Smith A, Pexsters A, Stalder C, Mclndoe A, Ghaem-Maghami S, Lees C, Brolmann HA, et al. Standardized approach for imaging and measuring cesarean section scars using ultrasonography. Ultrasound Obstet Gynecol. 2012;39(3):252-9. https://doi.org/10.1002/uog.10077.

5. Borges LM, Scapinelli A, de Baptista DD, Lippi UG, Coelho Lopes RG. Findings in patients with postmenstrual spotting with prior cesarean section. J Minim Invasive Gynecol. 2010;17(3):361-4. https://doi.org/10.1016/ j.jmig.2010.02.007.

6. Thurmond AS, Harvey WJ, Smith SA. Cesarean section scar as a cause of abnormal vaginal bleeding: diagnosis by sonohysterography. J Ultrasound Med. 1999:18(1):13-6 quiz 17-18.

7. Wang CB, Chiu WW, Lee CY, Sun YL, Lin YH, Tseng CJ. Cesarean scar defect: correlation between cesarean section number, defect size, clinical symptoms and uterine position. Ultrasound Obstetrics Gynecol. 2009;34(1): 85-9. https://doi.org/10.1002/uog.6405.

8. Florio P, Gubbini G, Marra E, Dores D, Nascetti D, Bruni L, Battista R, Moncini I, Filippeschi M, Petraglia F. A retrospective case-control study comparing hysteroscopic resection versus hormonal modulation in treating menstrual disorders due to isthmocele. Gynecol Endocrinol. 2011;27(6):434-8. https:// doi.org/10.3109/09513590.2010.495431.

9. Tahara M, Shimizu T, Shimoura H. Preliminary report of treatment with oral contraceptive pills for intermenstrual vaginal bleeding secondary to a cesarean section scar. Fertil Steril. 2006;86(2):477-9. https://doi.org/10.1016/j. fertnstert.2006.01.020.

10. van der Voet LF, Vervoort AJ, Veersema S, BijdeVaate AJ, Brolmann HA, Huirne JA. Minimally invasive therapy for gynaecological symptoms related to a niche in the caesarean scar: a systematic review. BJOG. 2014;121(2): 145-56. https://doi.org/10.1111/1471-0528.12537.

11. Vervoort AJ, Van der Voet LF, Witmer M, Thurkow AL, Radder CM, van Kesteren PJ, Quartero HW, Kuchenbecker WK, Bongers MY, Geomini PM, et al. The HysNiche trial: hysteroscopic resection of uterine caesarean scar defect (niche) in patients with abnormal bleeding, a randomised controlled trial. BMC Womens Health. 2015;15:103. https://doi.org/10.1186/s12905-0150260-8.

12. Shih $C L$, Chang $Y Y$, Ho M, Lin WC, Wang AM, Lin WC. Hysteroscopic transcervical resection. A straightforward method corrects bleeding related to cesarean section scar defects. Am J Obstetrics Gynecol. 2011;204(3):278 e271-272. https://doi.org/10.1016/j.ajog.2010.11.031. 
13. Bij de Vaate AJM, Brölmann HAM, van der Voet LF, van der Slikke JW, Veersema S, Huirne JAF. Ultrasound evaluation of the Cesarean scar: relation between a niche and postmenstrual spotting. Ultrasound Obstetrics Gynecol. 2011:37(1):93-9. https://doi.org/10.1002/uog.8864.

14. Li C, Tang S, Gao X, Lin W, Han D, Zhai J, Mo X, Zhou L. Efficacy of combined laparoscopic and Hysteroscopic repair of post-cesarean section uterine diverticulum: a retrospective analysis. Biomed Res Int. 2016;2016: 1765624. https://doi.org/10.1155/2016/1765624.

15. Feng $Y L$, Li MX, Liang XQ, Li XM. Hysteroscopic treatment of postcesarean scar defect. J Minim Invasive Gynecol. 2012;19(4):498-502. https://doi.org/10 1016/j.jmig.2012.03.010.

16. Gubbini G, Centini G, Nascetti D, Marra E, Moncini I, Bruni L, Petraglia F, Florio P. Surgical hysteroscopic treatment of cesarean-induced isthmocele in restoring fertility: prospective study. J Minim Invasive Gynecol. 2011;18(2): 234-7. https://doi.org/10.1016/j.jmig.2010.10.011.

17. Schepker N, Garcia-Rocha GJ, von Versen-Hoynck F, Hillemanns P, Schippert C. Clinical diagnosis and therapy of uterine scar defects after caesarean section in non-pregnant women. Arch Gynecol Obstet. 2015;291(6):1417-23. https://doi.org/10.1007/s00404-014-3582-0.

18. Fabres C, Arriagada P, Fernandez C, Mackenna A, Zegers F, Fernandez E. Surgical treatment and follow-up of women with intermenstrual bleeding due to cesarean section scar defect. J Minim Invasive Gynecol. 2005;12(1): 25-8. https://doi.org/10.1016/j.jmig.2004.12.023.

19. Wang CJ, Huang HJ, Chao A, Lin YP, Pan YJ, Horng SG. Challenges in the transvaginal management of abnormal uterine bleeding secondary to cesarean section scar defect. Eur J Obstet Gynecol Reprod Biol. 2011;154(2): 218-22. https://doi.org/10.1016/j.ejogrb.2010.10.016.

20. Qin $L$. The analyze of the efficacy of the three operation method in treating patients with uterine inCISlon diverticulum: Zhengzhou University.

21. Ofili-Yebovi D, Ben-Nagi J, Sawyer E, Yazbek J, Lee C, Gonzalez J, Jurkovic D. Deficient lower-segment cesarean section scars: prevalence and risk factors. Ultrasound Obstet Gynecol. 2008;31 (1):72-77. https://doi.org/10.1002/uog.5200

22. Osser OV, Jokubkiene L, Valentin L. High prevalence of defects in cesarean section scars at transvaginal ultrasound examination. Ultrasound Obstetrics Gynecol. 2009;34(1):90-7. https://doi.org/10.1002/uog.6395.

23. Li J, Deng L. Endometrial preconditioning with vacuum suction before Hysteroscopic resection. Tianjin Med J. 2005;33(1):54.

24. Duan H. Gynecological hysteroscopy diagnosis and treatment. Chinese J Obstetrics Gynecol. 2012;47(7):555-8.

25. Zhou J, Yao M, Wang H, Tan W, Chen P, Wang X. Vaginal repair of cesarean section scar diverticula that resulted in improved postoperative menstruation. J Minim Invasive Gynecol. 2016;23(6):969-78. https://doi.org/ 10.1016/j.jmig.2016.06.013.

\section{Publisher's Note}

Springer Nature remains neutral with regard to jurisdictional claims in published maps and institutional affiliations.

Ready to submit your research? Choose BMC and benefit from:

- fast, convenient online submission

- thorough peer review by experienced researchers in your field

- rapid publication on acceptance

- support for research data, including large and complex data types

- gold Open Access which fosters wider collaboration and increased citations

- maximum visibility for your research: over $100 \mathrm{M}$ website views per year

At $\mathrm{BMC}$, research is always in progress.

Learn more biomedcentral.com/submissions 